|| Print ISSN: 2589-7837 || Online ISSN: 2581-3935 ||

International Journal of Medical Science and Diagnosis Research (IJMSDR)

Available Online at www.ijmsdr.com

NLM (National Library of Medicine ID: 101738824)

Original Research Article

Volume 5, Issue 11; November:2021; Page No. 21-24

\title{
ABO Blood Group as a Potential Risk Factor for Dental Caries: A Cross- Sectional Study
}

\author{
Dr. Afreen Jan', Dr. Dipanshu Aggarwal'², Dr. Kriti Pallavi ${ }^{3}$, Dr. Asifa Ashraf ${ }^{4}$, \\ Dr. Poonam Waghmode ${ }^{5}$, Malik Aqueel Ahmed Khan ${ }^{6}$
}

${ }^{1}$ MDS, Senior Research Fellow, Indian Council of Medical Research (ICMR), AIIMS, New Delhi

${ }^{2}$ PG Scholar in MDS Program, Department of Oral Pathology and Microbiology, ITS-CDSR, Muradnagar, Ghaziabad

${ }^{3}$ MDS, Senior Research Fellow, Indian Council of Medical Research (ICMR), AIIMS, New Delhi

${ }^{4}$ MDS, Senior Research Fellow, Indian Council of Medical Research (ICMR), AIIMS, New Delhi

${ }^{5}$ BDS, Private Clinician

63rd PG (MDS), Al Bader Rural Dental College and Hospital. Gulbarga, Department of Oral

Pathology

Conflicts of Interest: Nil

Corresponding author: Dr. Dipanshu Aggarwal

DOI: https://doi.org/10.32553/ijmsdr.v5i11.874

Abstract:

Introduction: Dental caries is a multifactorial disease that affects people of all ages due to a complex interplay between genetic and environmental variables. The significance of genetics in an individual's vulnerability to caries has recently been explored in scientific literature. One such inherited genetic characteristic is blood group. The relationship between blood type, lifestyle, and dental caries may shed light on the above idea.

Aim: To explore into blood type as a possible risk factor for the development of dental caries.

Material And Methods: Blood samples from 39 people of the index ages (5, 12, 15, 35-44, and 6074 years) were taken, and blood grouping was done before oral screening to determine the DMFT index. A self-administered questionnaire was used to conduct a complete diet analysis. SPSS software was used to do statistical analysis on the data.

Results: In different age groups, there was a strong link between different blood types, DMFT index, and diet.

Conclusion: The current study's results demonstrate that genetic and epigenetic variables play a significant influence in the development of dental caries. As a result, blood groups can be utilised to detect if a certain diet is associated with the development of dental caries.

Keywords: Dental caries, ABO antigens, Blood group, DMFT index, risk predictors

\section{Introduction:}

Dental caries is a multifactorial illness that affects people of all ages due to a complex combination of genetic and environmental variables. Dental caries is caused by the interaction of cariogenic organisms, fermentable carbohydrates, and the vulnerable tooth, as well as other factors such as improper feeding habits. Individuals who are more sensitive to caries and others who are resistant to the development of caries exist, regardless of their exposure to these risk factors. The significance of 
genetics in an individual's vulnerability to dental caries has been explored in recent scientific research. One such inherited genetic characteristic is blood group. The relationship between blood type, diet, and dental caries throws light on the mechanisms suggested. The purpose of the study is to see if blood type can be used to predict dental caries risk in patients of various ages.

\section{Materials \& Method}

Blood group was determined of 39 subjects from different index age groups. Oral examination was done to calculate the DMFT (Decayed, Missing, Filled Tooth) score of the individuals. A selfadministered questionnaire was used to conduct a complete diet analysis. Patients with any type of systemic illness or congenital condition and malocclusion were excluded from the study. The data was statistically examined by SPSS V20.0.0.

\section{Results}

Individuals with the AB blood group had a higher DMFT score than those with the O blood group, which had the lowest. The Kruskal-Wallis test was used to compare the DMFT scores and blood groups among groups. $\mathrm{P}=0.005$ was found to be a statistically significant difference. Table 1 shows the results used to compare the DMFT scores between the four blood groups.

Table 1: Prevalence of caries among various blood groups in the study groups

\begin{tabular}{|l|l|l|l|}
\hline \multirow{2}{*}{ Blood group } & Caries & \multirow{2}{*}{ p-value } \\
\cline { 2 - 3 } & Absent & Present & \\
\hline A & 3 & 3 & \multirow{2}{*}{$0.005(\mathrm{~S})$} \\
\hline B & 2 & 4 & \\
\hline AB & 2 & 15 & \\
\hline O & 9 & 1 & \\
\hline
\end{tabular}

\section{Discussion}

The focus of dental caries aetiology is turning to host-related risk factors - "the Genetics." Chronic illness sensitivity to $\mathrm{ABO}$ blood grouping is thought to be the genetic foundation for familial propensity. Various studies have shown that sugars and other fermentable carbohydrates have a role in the start of dental caries. ${ }^{[1]}$ In this study, participants were asked about their eating habits, such as snacking in between meals, sweet intake, fruit consumption, and other carbonated beverages. Landsteiner categorised blood groups into four groups in 1900, explaining the existence of serological variations between people based on the presence or absence of distinct agglutinogen (antigen A, B) on the surface of red blood cells. ${ }^{[2]}$ The ABO gene, which is found on the long arm of the 9th chromosome, regulates blood types inherited from parents. The ABO blood system is responsible for determining the body's immunological features. The increased amounts of antibodies generated against the bacteria might be one reason for the lower occurrence of dental caries in people of a certain blood type. Antigen A is found on the RBC of people with the A blood type, antigen $\mathrm{B}$ on the $\mathrm{RBC}$ of people with the $\mathrm{B}$ blood group, both $\mathrm{A}$ and $\mathrm{B}$ on the $\mathrm{RBC}$ of people with the $A B$ blood group, and no antigens on the $\mathrm{RBC}$ of people with the $\mathrm{O}$ blood group. Blood type $\mathrm{O}$ has anti-A and anti-B antibodies, which protect against certain types of bacteria that cause tooth decay, resulting in a decreased incidence of dental caries. AB, on the other hand, has no antibodies related with an increased frequency of dental caries, which is consistent with the findings of this investigation.

Mavridis and Achimastos discovered that secretors had greater mean DMFT, although the difference was not significant. In a large Chilean population, Barros and Witkop discovered no link between DMFT and $\mathrm{ABO}$ and MN blood types, however Arneberg et al. discovered decreased caries frequency for secretors regardless of blood group, with a more obvious difference for smooth 
surfaces (i.e., oral or vestibular tooth surfaces). Holbrook and Blackwell discovered considerably lower DMF in secretors than nonsecretors in a cohort of young Icelanders. ${ }^{[3-6]}$

Several studies have shown that ABO blood types, particularly non-O blood groups, are linked to the risk of ischemic heart disease and severe atherosclerotic symptoms in recent years. ${ }^{[7,8]}$ Individuals in the $\mathrm{O}$ group $(\mathrm{A}, \mathrm{AB}$, and $\mathrm{B})$ have a 14 percent lower risk of squamous cell carcinoma and a $4 \%$ lower risk of basal cell carcinoma than those in the non-O group (A, AB, and $\mathrm{B})$. It has also been linked to a lower risk of pancreatic cancer. ${ }^{[9]}$ According to Glass et al., those with the O blood type have a higher chance of contracting cholera, and those who do have it have more severe illnesses. ${ }^{[10]}$

As a result, while various studies have been conducted to study the relationship between $\mathrm{ABO}$ blood types and illness incidence in medicine, there has been little research done to investigate the relationship between $\mathrm{ABO}$ blood groups and the occurrence of oral disorders. In our study, the investigation of the relationship between blood and dental caries found that there is a link between blood types and dental caries.

Singla et al. investigated the relationship between dental caries and blood group in the western Punjab population of India in 2015, finding that the prevalence of dental caries was greater in the $A$ and $\mathrm{B}$ blood groups and lower in the $\mathrm{O}$ and $\mathrm{AB}$ blood groups. He also mentioned that blood type has a role in the development of dental caries. ${ }^{[11]}$

Mazumdar et al. (2014) proposed that ABO blood group compounds produced in saliva lead to assembly of microorganisms and their departure from the oral cavity, which might explain the high association between blood group, secretor status, and dental caries. As a result, the production of $\mathrm{ABO}(\mathrm{H})$ antigens into saliva may interfere with bacteria's ability to stick to the tooth surface. ${ }^{[12]}$

Bakare's assertion that $\mathrm{ABO}$ variants may play a key role in immunology and illness prevention appears to be correct. To definitively prove their etiogenic significance, multicenter collaborative research involving multiple demographic groupings are needed to further investigate this relationship internationally. ${ }^{[13]}$

\section{Conclusion}

According to the findings of this study, there is a substantial link between blood types and the onset of dental caries. As a result, blood types may be a risk factor for the development of dental caries. People with the AB blood type are more likely to acquire dental caries. However, Individuals with the $\mathrm{O}$ blood type have a lower risk of developing dental caries. Our findings back with previous research that revealed $\mathrm{ABO}$ antigen secretion to be caries-protective. These findings are unusual in that they suggest that salivary ABO secretion may have a role in the preservation of primary teeth, although more study is needed to corroborate this conclusion, particularly into the background processes.

\section{References}

1. Aas JA, Griffen AL, Dardis SR, Lee AM, Olsen I, Dewhirst FE, Leys EJ, Paster BJ: Bacteria of dental caries in primary and permanent teeth in children and young adults. J Clin Microbiol 2008; 46: 1407-1417.

2. Landsteiner $\mathrm{K}$ : Zur Kenntnis der antifermentativen, lytischen und agglutinierenden

3. Mavridis N, Achimastos A: Secretor status and dental caries. J Dent Res 1974; 53: 949.

4. Barros L, Witkop CJ Jr: Oral and genetic study of Chileans 1960. III. Periodontal disease and nutritional factors. Arch Oral Biol 1963; 8: 195-206.

5. Arneberg P, Kornstad L, Nordbo H, Gjermo P: Less dental caries among secretors than among non-secretors of blood group substance. Scand J Dent Res 1976; 84: 362-366.

6. Holbrook WP, Blackwell CC: Secretor status and dental caries in Iceland. FEMS Microbiol Immunol 1989; 1: 397-399.

7. Akhund IA, Alvi IA, Ansari AK, Mughal MA, Akhund AA. A study of relationship of ABO blood groups with myocardial infarction and angina pectoris. J Ayub Med Coll Abbottabad 2001;13:25-6. 
8. Nydegger UE, Wuillemin WA, Julmy F, Meyer BJ, Carrel TP. Association of ABO histo-blood group B allele with myocardial infarction. Eur J Immunogenet 2003;30:201-6.

9. Wolpin BM, Kraft P, Gross M, Helzlsouer K, Bueno-de-Mesquita HB, Steplowski E, et al. Pancreatic cancer risk and ABO blood group alleles: Results from the pancreatic cancer cohort consortium. Cancer Res 2010;70:101523.

10. Glass RI, Holmgren J, Haley CE, Khan MR, Svennerholm AM, Stoll BJ, et al. Predisposition for cholera of individuals with O blood group. Possible evolutionary signifi cance. Am J Epidemiol 1985;121:791-6.
11. Singla S, Verma A, Goyal S, Singla I, Shetty A. Correlation of dental caries and blood group in Western Punjab population in India. Indian J Multidiscip Dent 2015;5:59-61.

12. Mazumdar P, Das UK, Goswami S. Correlation between blood group and dental caries in 20-60 years age group:A study. IJAR. 2014; 2: 413-24.

13. Bakare AA, Azeez MA, Agbolade JO. Gene frequencies of $\mathrm{ABO}$ and rhesus blood groups and haemoglobin variants in Ogbomoso, South-West Nigeria. Afr J Biotechnol 2006;5:224-9. 